\title{
Elaboration of the Hydro-Geophysics GIS Showing the Volubilis Depression and the Prerifains Ridges Structuration (Morocco North Occidental)
}

\author{
Asma Ben Moussa', ${ }^{1,2}$, Abdelaziz Mridekh', Bouabid El Mansouri' ${ }^{1}$ Ahmed Manar³, \\ Mohamed Chibout ${ }^{4}$ \\ ${ }^{1}$ Laboratory of Applied Geosciences, Technology Team of Water Resources, Faculty of Science, IbnTofail \\ University, Kenitra, Morocco \\ ${ }^{2}$ International Institute of Water and Waste Water, O.N.E.E-Water Sector, Chellah, Morocco \\ ${ }^{3}$ Ministry of the Energies, Mines, Water and the Environment, Rabat, Morocco \\ ${ }^{4}$ Laboratory of Geodynamic, Faculty of Science, Dhar Mehraz University, Fes, Morocco \\ Email: abdelaziz.mridekh@gmail.com, b_elmansouri@yahoo.fr, asmabemoussa@gmail.com, \\ a2manar@yahoo.fr, medsaid@gmail.com
}

Received 22 May 2015; accepted 23 June 2015; published 26 June 2015

Copyright (C) 2015 by authors and Scientific Research Publishing Inc.

This work is licensed under the Creative Commons Attribution International License (CC BY). http://creativecommons.org/licenses/by/4.0/

(c) (i) Open Access

\begin{abstract}
We present a comparative analysis of electrical and gravity data on the Geographic Information System of the prerifaines ridges. At the Meso-Cenozoïc sequence, the geometry of the prerifaines ridges is fairly well known. However, the post-Miocene series remain to be characterized. In this perspective, we use a database composed of gravity and vertical electrical sounding profiles and geo-electrical sections in order to characterize this structuration. These data are calibrated by many oil and hydrogeological boreholes. Preliminary results lead to better understanding of the organization of its underlying structures in this area. The Gravimetric filtering results show that the area may be dissected by tree major faults striking NW-SE, NE-SW and N-S. All these faults have contributed, since Hercynian to Alpines orogenies, to the structuring of this area, being proved to be the deepest and can reach $4500 \mathrm{~m}$. The comparison of gravity maps, geological and structural maps under Geographic Information System allows the identification of major structural directions and trends of the study area. It confirms some structural elements gathered from outcrops and define new ones. Results from this work show the importance of using various filtering and interpretation techniques in the analysis of gravity data. They also provide news insights into the deep structure of the study area.
\end{abstract}




\section{Keywords}

\section{Prerifaines Ridges, Volubilis, Miocene, Electric, Gravimetric, GIS Hydro-Geophysics}

\section{Introduction}

The Prerif ridges (Ridges Prérifaines [1]; or Ridges Sud-rifaines [2]) are part of the south western front of the Rif thrust belt. It is limited to the South and the South East by the lacustre-palustre basin of Saiss, to the west by the Rharb basin, to the north and to the east by the Rif fold. The Ridges are divided into two groups (Figure 1): a first Western group curved and directed toward the west (Outita, Bou Azzouf, Nouillat, Aïn Jemaa, El Kansera, Bou Draa, Balass, Jbel Ari and Kefs), and a second Oriental group that forms a less accentuated arc (My Driss Zerhoun, BouKannfoud, Tselfat, Dhar N’sour, Nesrani, Takerma Kennoufa and Fert El Bir) [1].

The study area was subject of numerous studies since the early 20th century. The studies involved the analysis of the surface outcrops [1]-[4], and the subsurface data [2]-[4] [6].

A geodynamic history of the area of study is with the first manifestations of the separation of the American and African continent. The Prerif ridges have been, for a long time, interpreted as the Mesozoic material thrust sheets of the head Rif region, thrust sheets that are poured unto the south and the southwest. These thrust sheets are the result of a synchronous Tortonian compression phase in the development of the Prerif nappe [3] [4] [7] [8]. The first tectonic models have considered ridges as simple asymmetric structures [9] or as flat detachment structures. Other authors [3]-[10] have considered these separations as tectonic structures, that materialize the Rif outermost frontal thrust [9] or a flat detachment with frontal amortization [10]. In the majority of the above-mentioned work, deposits of the Miocene and the Plio-Quaternary have only been treated from the outcrop. Structural studies have shown that the stress fields are oriented NE-SW, N-S and NW-SE. Three types of

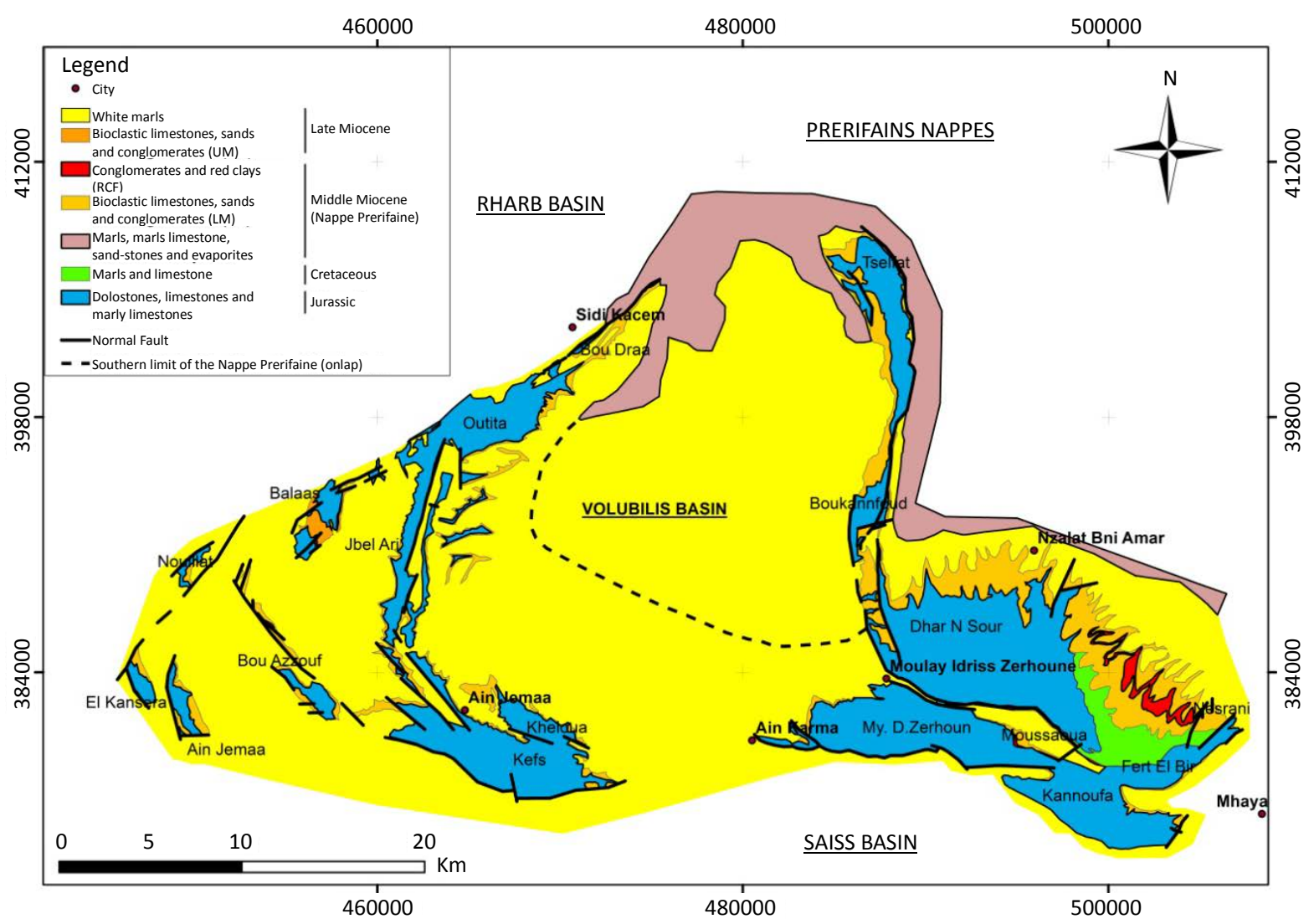

Figure 1. Geographical and geological location of the study area. 
deformations are described: the radial distensive, which are the oldest within the internal areas; the oblique compressive deformation at the front of the Western ridges, and finally, the distensive deformations at the front of the Eastern ridges [2]. It was also demonstrated that ridges show typical structural geometric characteristics of the propagation folds [4] [5].

In previous studies, the subsurface mio-plio-quaternary series were not discussed in details, because of the resolution of the seismic, widely used in oil exploration [6]-[8]. The use of geophysical methods for imaging in detail the structures with shallow depth, and their relationships with the deep structures, is required. The objective of this work covers, thus, the precise determination of the geometry of the depression of Volubilis, and the recent structures that have contributed to its development. All of this, through the integration and the re-interpretation of geophysical data: gravimetric, electric and seismic.

\section{Lithostratigraphy}

The Mesozoic series age attributions are mainly due to the works of [4]-[6]. We briefly present the Meso-Cenozoic series by focusing on the Mio-Plio-Quaternary one.

Thus, the sedimentary series of the Jurassic are very varied and consist of three units [1] which show the substantially facies that are compounds of limestone, marly limestone and marl. In the Cretaceous, the transgression led to the formation of marine sedimentary deposits that are of a clay marl and carbonated nature, based unconformably on the Jurassic lands. The thickness increases from south to north. The deposits of the Upper Miocene of Prerif ridges form a transgressed sedimentary set, slightly discordant on the Jurassic or the Cretaceous. The Miocene series present two to four formations that define a thick transgressif sequence of fourth order. The most complete stratigraphic log of these series of the study area includes from the top to down [4] (Figure 2).

- Middle-upper Miocene: inferior calcareous sandstones (inferior molasse or geological formation 1);

- Middle-upper Miocene: sandstones and brecciated red clays (continental Miocene,geological formation 2);

- Upper-terminal Miocene: superior calcareous sandstones (superior molasse, geological formation 3);

- Terminal Miocene: pelagic white marls (geological formation 4).

Stratigraphically, there are three types of Miocene sedimentary series: incomplete series (El Kansera, Takerma Kennoufa, Nesrani, Kefs, Outita and South and West of My. Driss Zerhoun and Fert El Bir), intermediate series (East and the North East of My. Driss Zerhoun and Fert El Bir), and the complete sets: My Yacoub, Dhar En N'sour and Tselfat [4].

\section{Methodology and Hydrogeophysical Geodatabase}

The built hydro-geophysical SIG targets the intersection of geological and geophysical data (electrical, gravity and seismic). For this matter, the approach involves the processing of alphanumeric data into cartographic data and the integration of different interpretive maps. The electrical method is based on the electric potential measurement, which is the result of applying an electric current in the subsoil. The resistivity surveys are carried out through an increasing inter-electrode distance quadrupole device (vertical electrical sounding, SEV) [11]. The interpretation of the SEV is not unique due to the principles of "equivalence" and "suppression" [2]. The Gravimetry is sensitive to the subsoil density variations. The gravity field varies greatly with altitude, this means that if we want to measure tiny variations, we should correct the instrument altitude measurements, which should be at best known a few mm close [11]. The processing and modeling of gravity measurements help to determine the physical parameters and the geometric shape of the bodies that are responsible of the pull of gravity variations (g), and help to characterize the geological structures, which know both lateral and in depth density variations. In order to illustrate the geometry of the study area deep structure, the used data include a recognition gravity survey on the Sais-Rharb region and its borders on behalf of Cherifien Company of Petroleum (CAG 1946-1949). For the mapping of the geological contacts, the faults and their spatial characteristics, six interpretation methods were used based on the residual anomaly map: the vertical gradient (first and second derivatives), the horizontal gradient, the up and down continuations of the residual anomaly, the Euler deconvolution and the Source Edge Detect (SED) [12].

The geo-electrical database consists of 107 vertical electrical soundings (SEV), AB lengths varying from $3000 \mathrm{~m}$ to $10,000 \mathrm{~m}$, and distributed over a regular grid of $1 \mathrm{~km} \times 2 \mathrm{~km}$. The processing and interpretation of those SEV has led to the realization of apparent resistivity maps at different AB/2 (100, 200, 300, 400, 1000, 


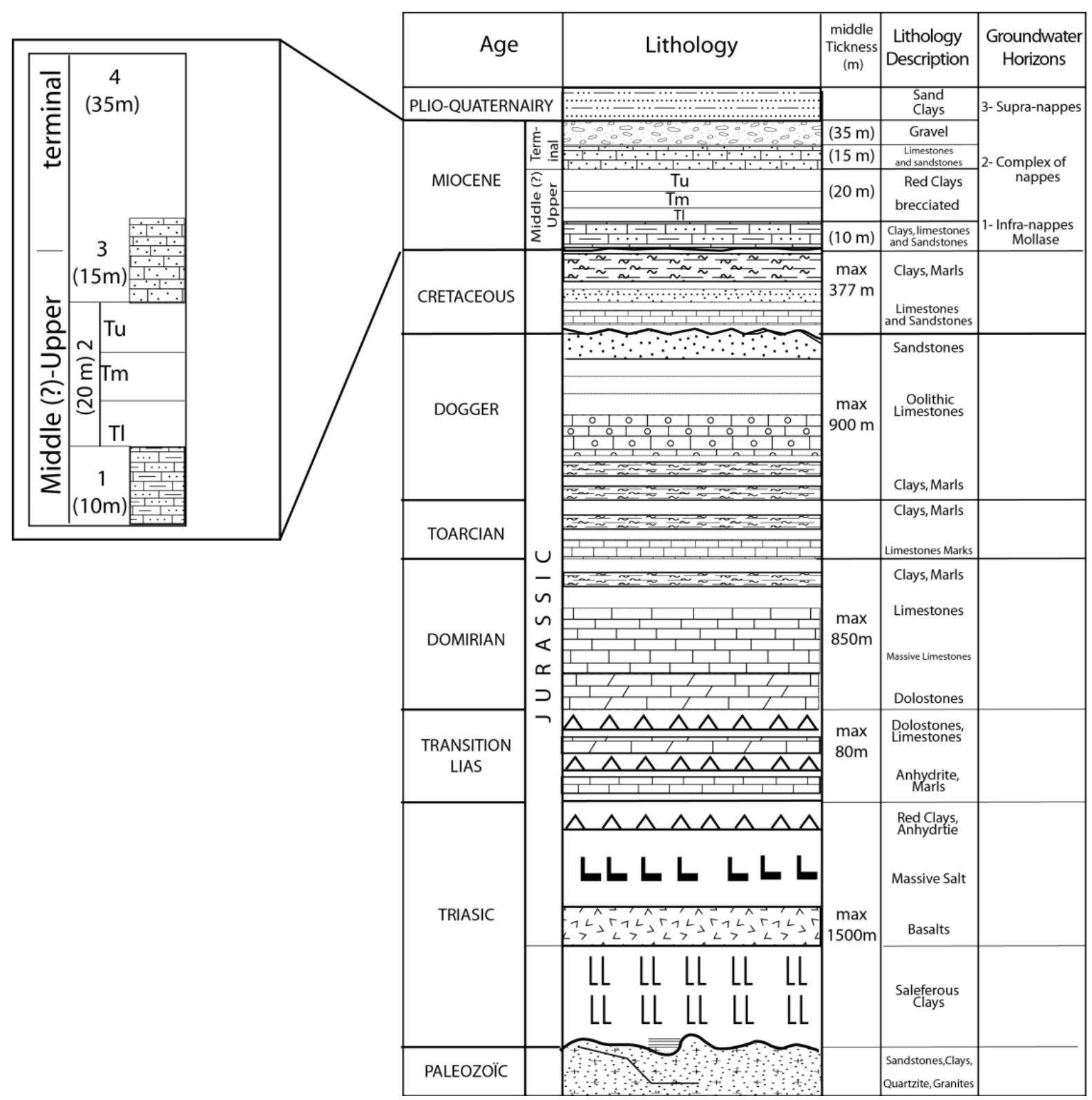

Figure 2. Stratigraphic log of the Meso-Cenozoic deposit of the Study area.

4000, 6000 m) (Figure 3) [15]. The African Company of Geophysics (CAG) has set up a recognition gravimetric survey on the Sais-Rharb region and its borders, on behalf of Cherifien Company of Petroleum (CCP) between 1946 and 1949. The gravimetric measurements that were exploited in this context were extracted from the residual anomaly map (scale 1/200,000) that corresponds to the study [13]. The base layers (topographic, geological, structural, hydrology systems, water (IRE) and petroleum drillings, MNT, extracted from Google Earth) have been digitized.

\section{Results and Discussions}

\subsection{Geometry of the Resistants Horizons}

The apparent resistivity maps for various AB/2 (Figure 4) were used to deduce that the electrically resistive horizons are distributed according to a sub-meridian direction. Their comparison with the residual anomaly map shows that they adopt a parallel geometry to the axis of a negative gravimetric anomaly; a North-South axis 


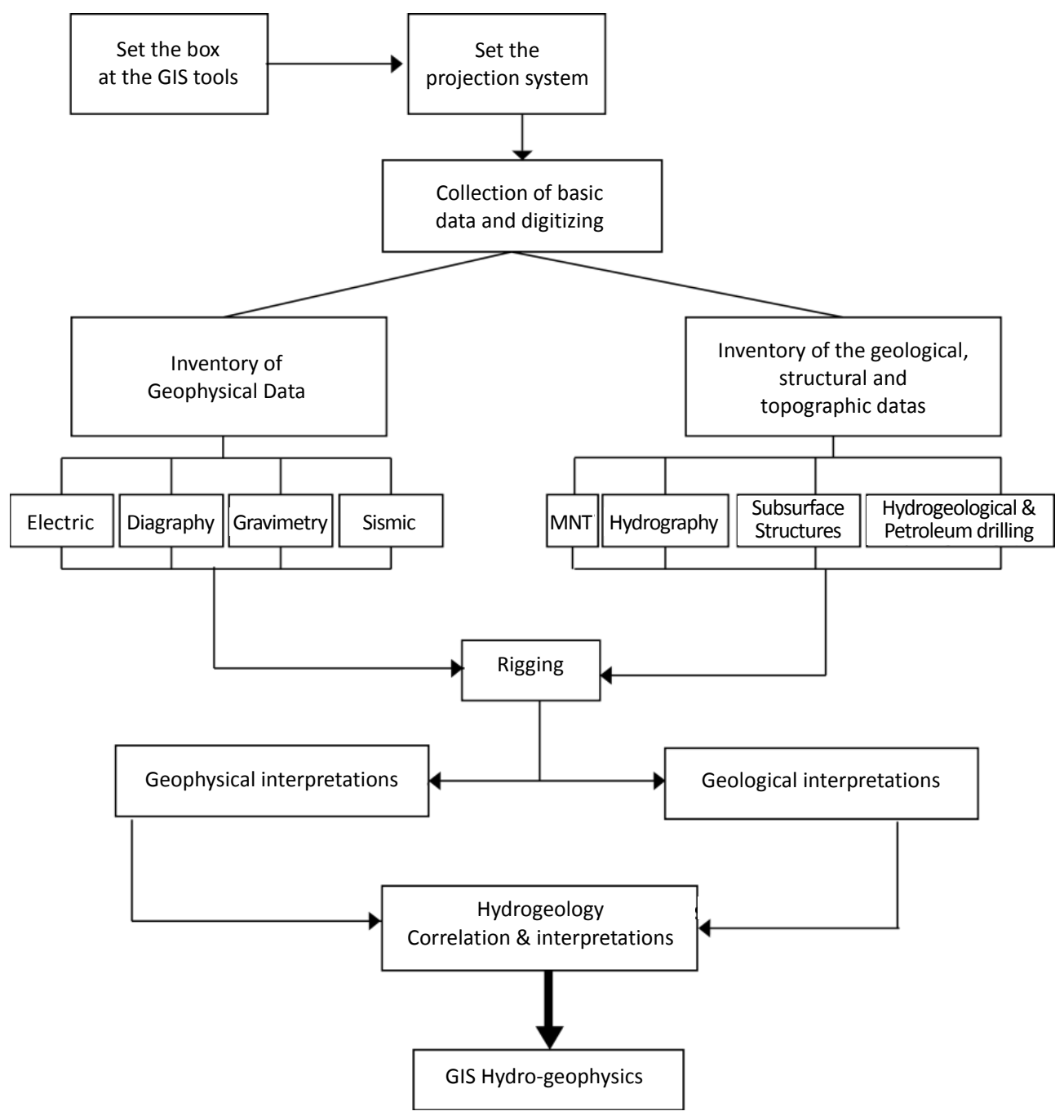

Figure 3. Methodology of elaboration of the hydro-geophysical SIG.

depression shifted eastwards and opened towards the south and south-west. Their geometry would then be controlled by the deep faults that are near of the southern Rif's ridges including the fault of Sidi Fili and Aïn Lorma.

The comparison of apparent resistivity maps at different depths shows that the depression persists and keeps a submeridian axis plunging towards the south. The confirmation of such dynamics is performed by the analysis and interpretation of a SEV section where the Miocene aged resistant R2 gets deeper from the West toward the East (Figure 4). Thus, and through the study of geo-electrical soundings, we have new data that allow to a better reassess of the hydrogeological potential of the plain of Volubilis and a localization of new areas with a promising hydrogeological potential especially at the North East sector level.

\subsection{Deep Structure of the Volubilis Depression}

The interpretation of gravimetric data, from the basin of Volubilis and the prerifaines ridges, highlights three compartments; two are of a high density and are interspersed by a light compartment (Figure 6). The positive gravity anomalies are associated with the Paleozoic socle and its heterogeneities, while the negative ones (relatively low) are the signature of sedimentary basins, and/or salt domes [10]. The application of the different treatments was used to map a large number of gravimetric contacts that materializes the density and/or faults discontinuities ... etc. The residual anomaly map, the location of hydro geological and oil drillings being superimposed, highlights the main gravity anomalies (P: positive $\mathrm{N}$ : negative) which are corresponding to the basin of Volubilis and the prerifaines ridges. The obtained directions of anomalies are NE-SW (Hercynian direction), 


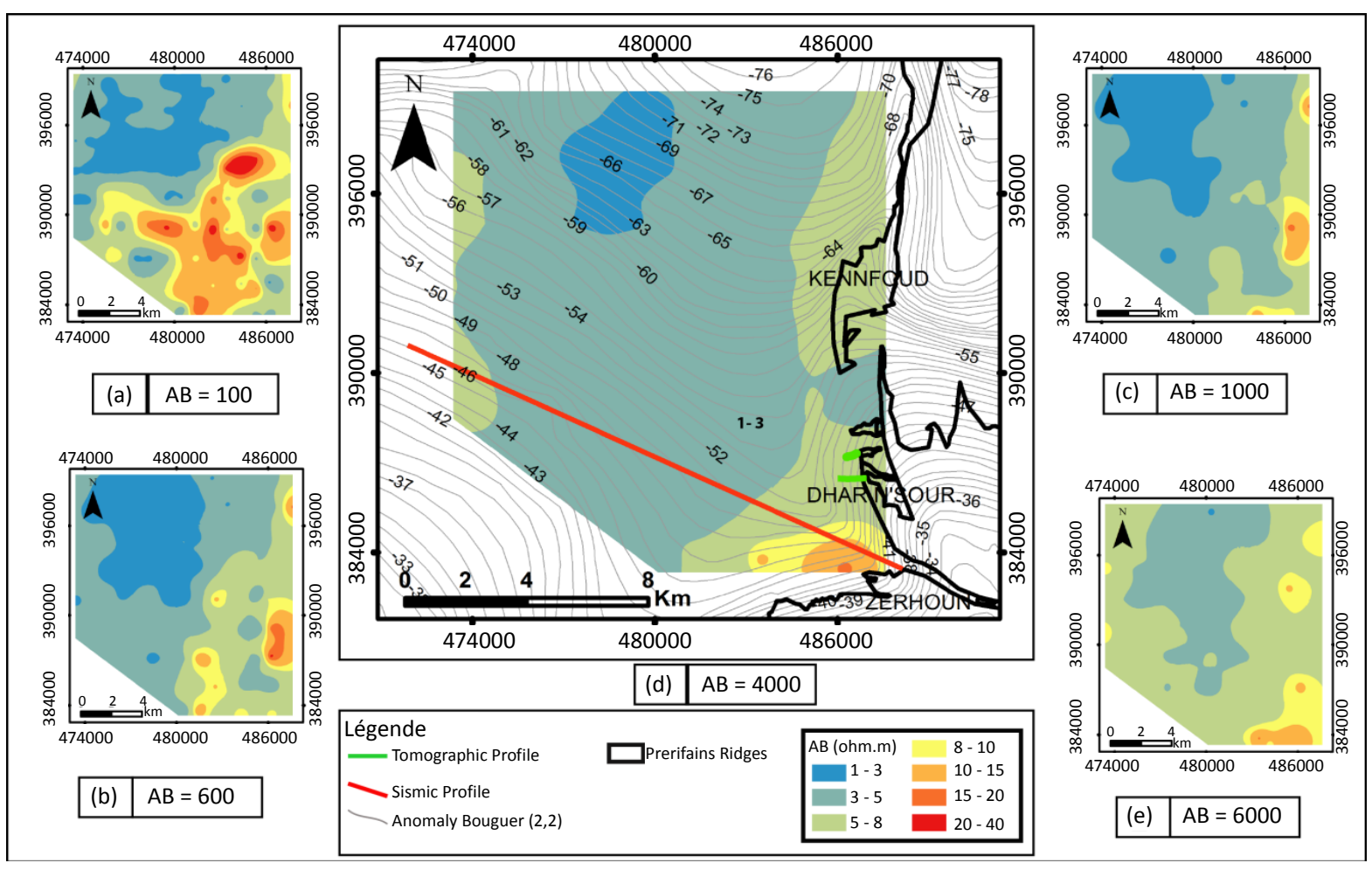

Figure 4. Maps of the apparent resistivity at different depth (a) $A B=100$, (b) $A B=600$, (c) $A B=1000$, (e) $A B=6000$. Superposition of the Bouguer anomaly map (CAG, 1947) and the apparent resistivity (d) $A B=4000$.

dominant and NS. Thus, the established maps allow to improve the knowledge of the deep structure of the study area and to provide a guide for the underground water resources exploration, particularly in the Miocene series of the region. The results were integrated into the hydro-geophysical GIS that was implemented in this study. According to these new data, the basin of Volubilis is due to a socle gravimetric anomaly, confirmed by the offset in depth of the Paleozoic horizon that reaches about $2849 \mathrm{~m}$ in OF2 against $660 \mathrm{~m}$ at the AL6 drilling (Figure 5).

\subsection{Lineaments of the Socle of the Prerifaines Ridges and the Deep Structure of the Volubilis Depression}

The main gravimetric anomalies of the study sector show, on one hand, that the western compartment is severely limited by a sub-meridian anomaly at the current location of the fault of Sidi Fili (Figure 6). On the surface, against this fault can be observed Mesozoic land successive bevels [2]. The western compartment is bordered by the fault of N'Zala Del Oudaya, parallel to the fault of Sidi Fili (Figure 6). On the other hand, they show seven negative anomalies (N1 to N7) and five positive ones (P1 to P5) (Figure 6). They correspond to anticlinal scales, associated with Jurassic outcrops. Note that, deep drilling has indicated the presence of growing diapirs in the ridges Jurassic cover [8]. Calculating the horizontal gradient helps to define the contours of the structures, as well as the gravimetric discontinuities [9]. The map (Figure 7(a)) illustrates the limits of the basin of Volubilis and those of the anomaly N2 which are characterized by a strong gradient. The horizontal gradient reaches its maximum at the base of the boundary between contrasting densities lithological units. It highlights areas where gravity is rapidly changing under the impact of changes in rock density. The comparison of apparent resistivity maps with those of the gravimetric anomaly illustrates the constancy of the position of the sub-meridian boundary between the oriental ridges and the depression of Volubilis.

The extension to the top that are based on the theoretical calculation of the residual anomaly map at a higher altitude [12], aims to separate the anomalies that are caused by the superficial sources from those caused by the deep sources, by attenuating the high frequencies that are generated by the surface sources, and favoring the large size sources (or large wavelengths) that are related to deep sources.The set of anomalies maps allows to 


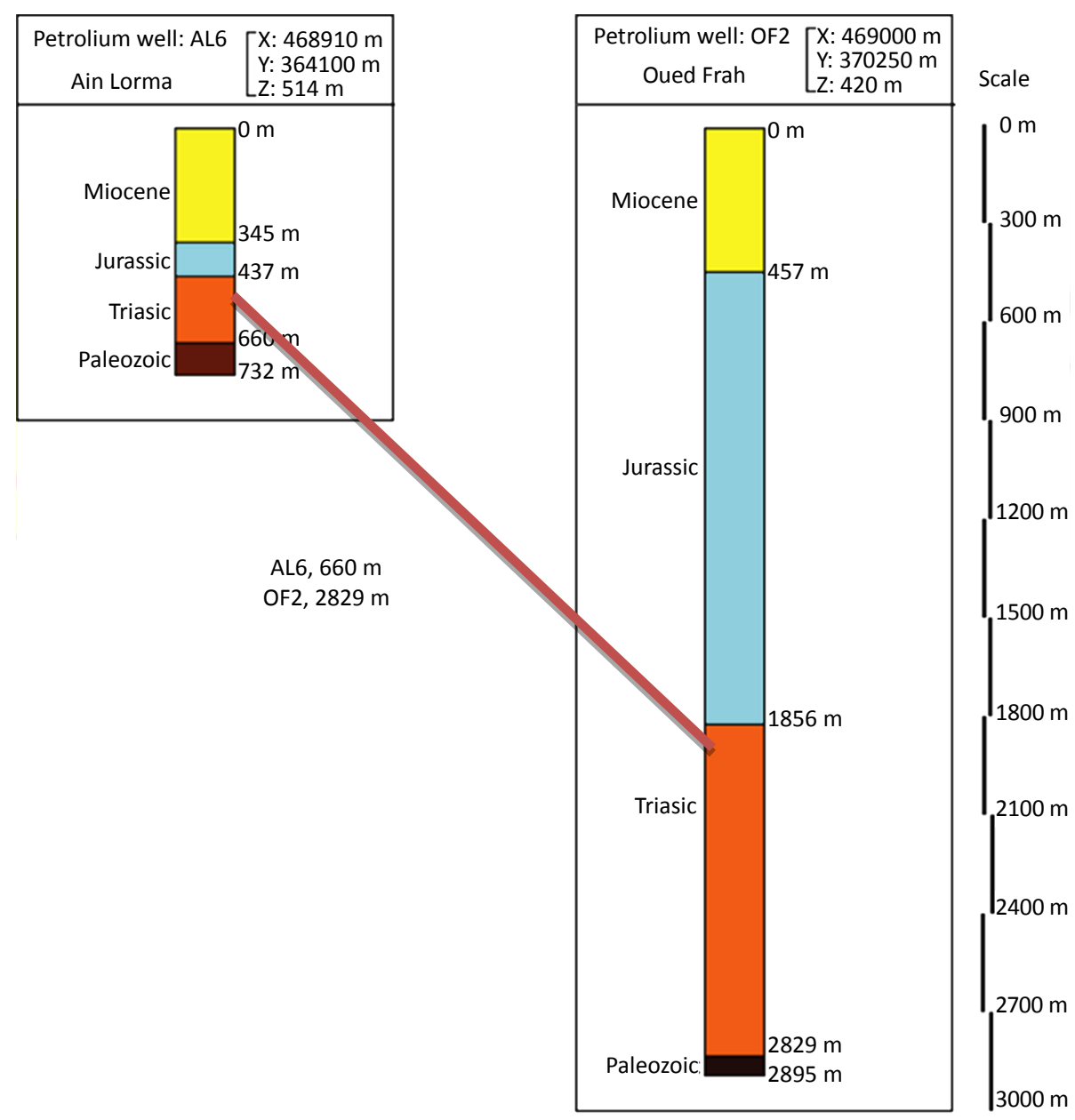

Figure 5. Difference of the paleozoic socle depth on the petroleum boreholes OF2 et AL6.

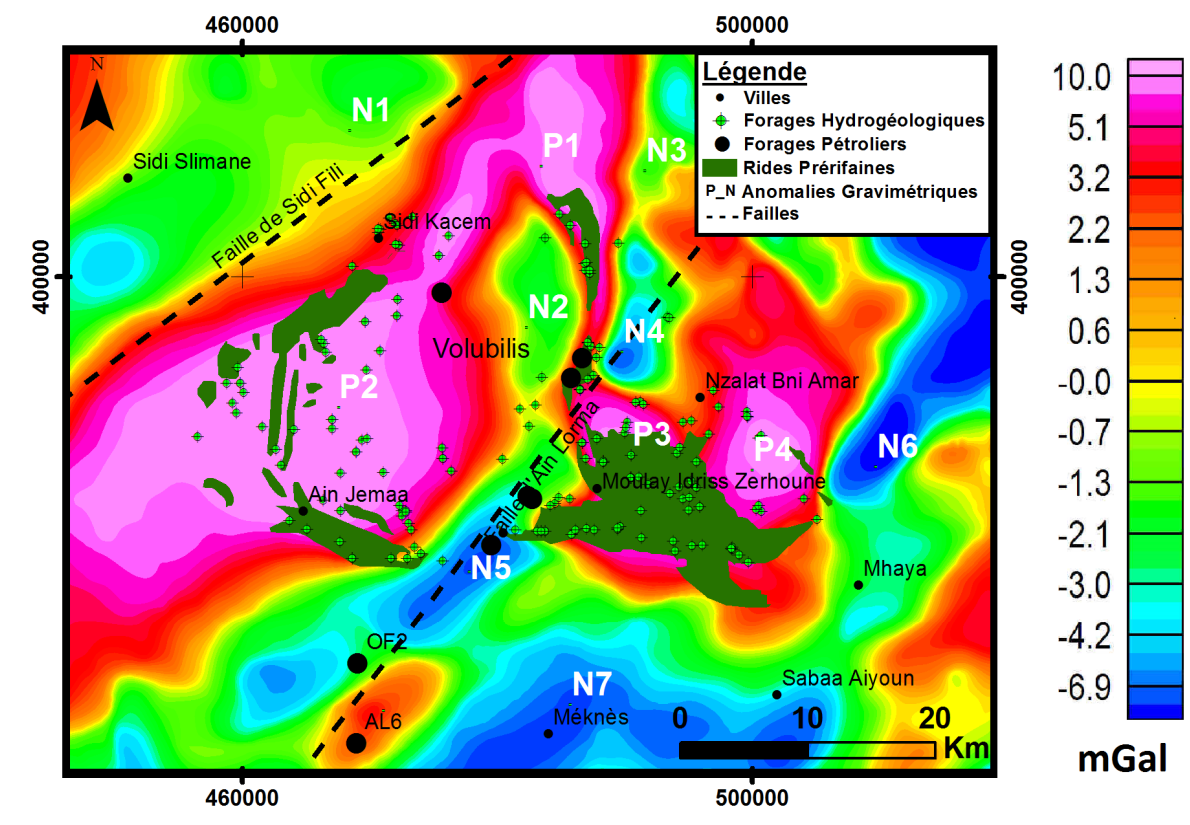

Figure 6. Residual anomaly map and the position of petroleum borehole OF2 et AL6. 


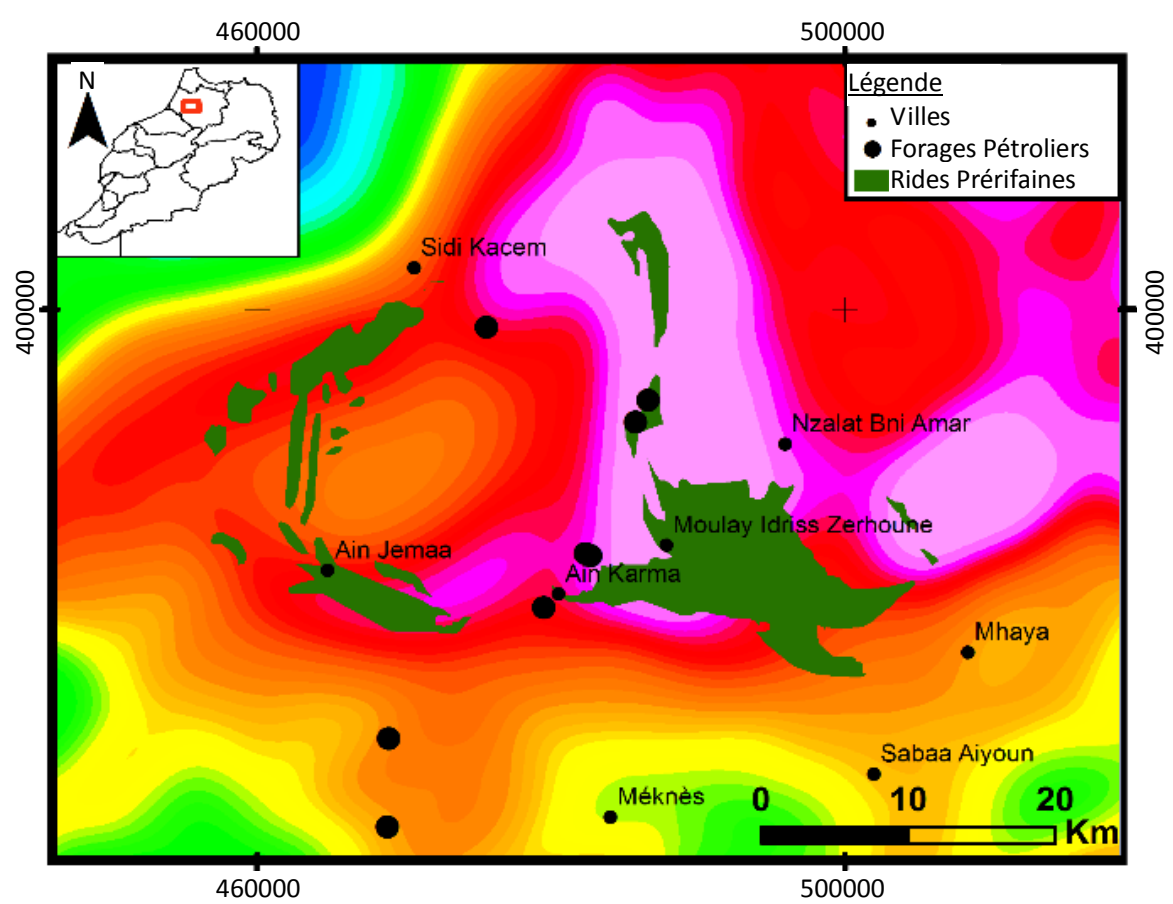

(a)

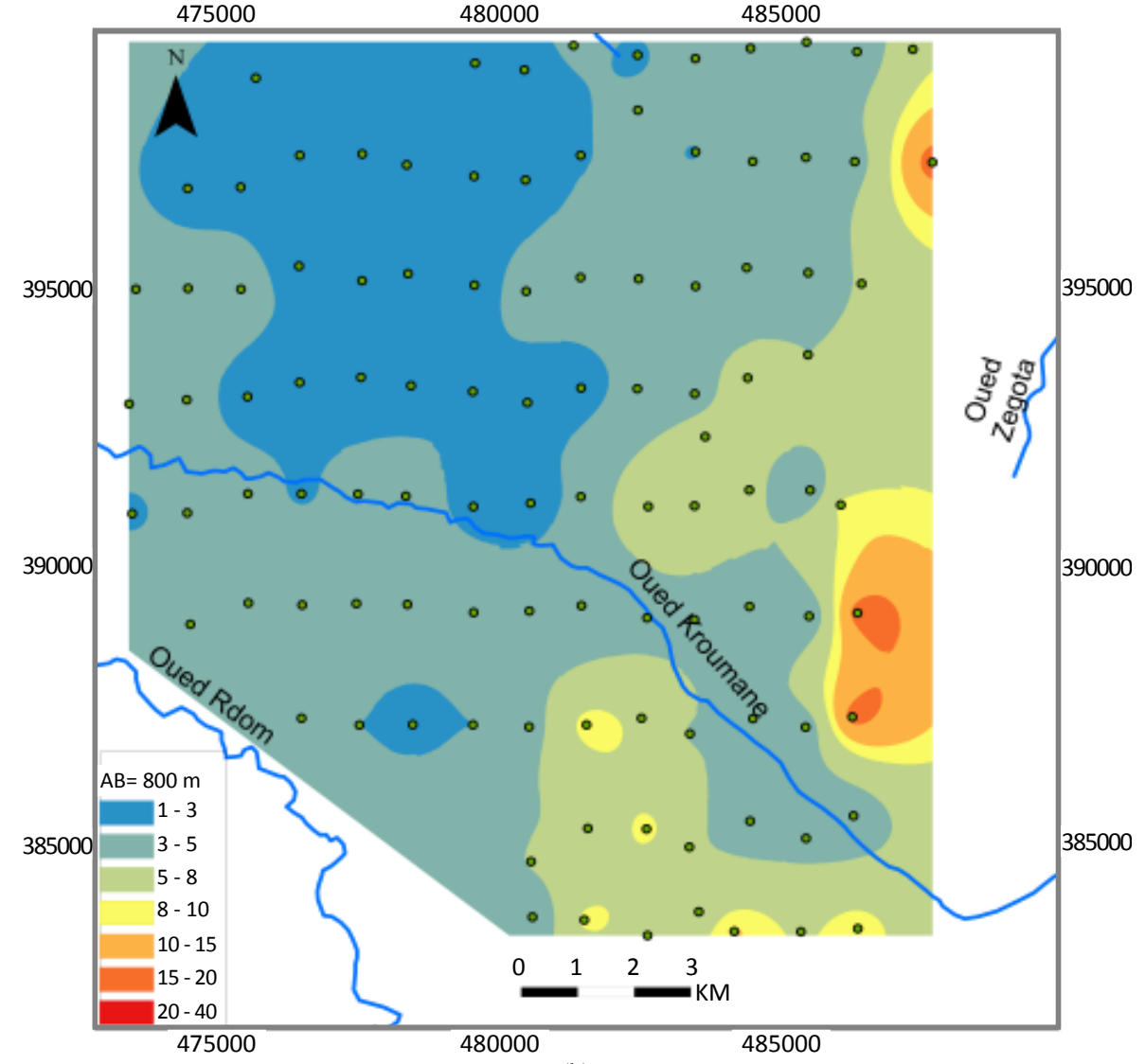

(b)

Figure 7. Map of horizontal gradient up continuation to $4000 \mathrm{~m}$ (a) compared of the map of apparent resistivity (part Est of Volubilis). (a) Map of the Horizontal Gradient up continuation to $4000 \mathrm{~m}$; (b) Resistivity apparent for $\mathrm{AB} / 2=800 \mathrm{~m}$. 
highlight the fact that the negative anomaly N2 (at the base of the depression of Volubilis) starts to disappear at a depth of $2000 \mathrm{~m}$ and completely disappears at a depth of $4000 \mathrm{~m}$ (Figure 8).

The establishment of the alignment of contacts allows highlighting the position and depth of the structures [14]. They indicate the existence of new faults, in addition to the main contacts previously deducted. Thus, Figure 8 shows that the deepest accidents are mainly directed NE-SW to NNE-SSW and others are directed NS, their depths can reach $3000 \mathrm{~m}$. The NS fault system is almost present; it consists of superficial faults which have a depth that doesn't exceed $1000 \mathrm{~m}$ at the plain of Volubilis. On the west and south sides of Eastern and Western ridges, Euler solutions allow the detection of faults with an estimated depth that varies from 1000 to $3500 \mathrm{~m}$ (Figure 9).

\section{Syntheis and Discussions}

In this work, we discussed the establishment of a hydro-geophysical GIS of the prerifaines ridges. This combination aims at the integration of geophysical data, in order to have an idea about the deep aquifers of the area. Thus, the residual anomaly map shows that the study area can be divided into three compartments; two compartments of a high density interspersed between a low density compartment. The residual anomalies map helped to identify five positive and five negative anomalies. Its upward extension allowed differentiating the superficial negative anomalies from those of a deep origin. The preliminary results show that the residual anomaly prolonged to $400 \mathrm{~m}$ indicates that the Pliocene-Quaternary cover has no influence on the residual anomaly.

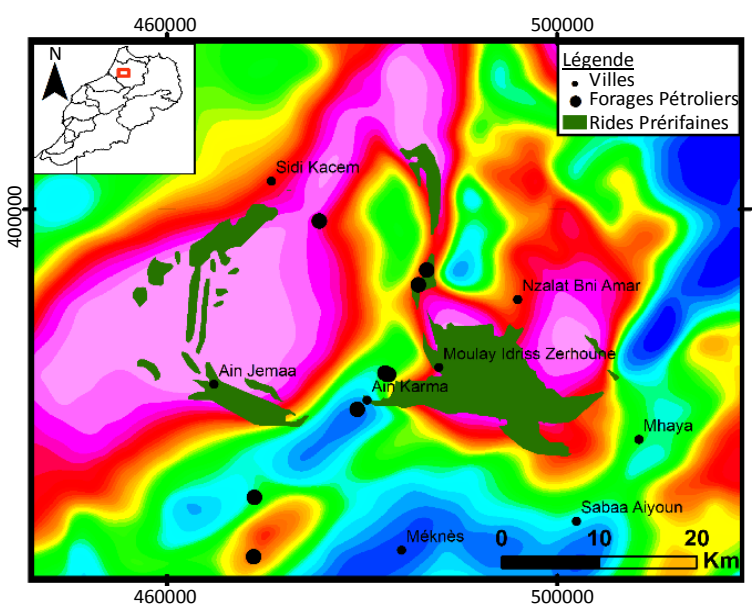

(a)

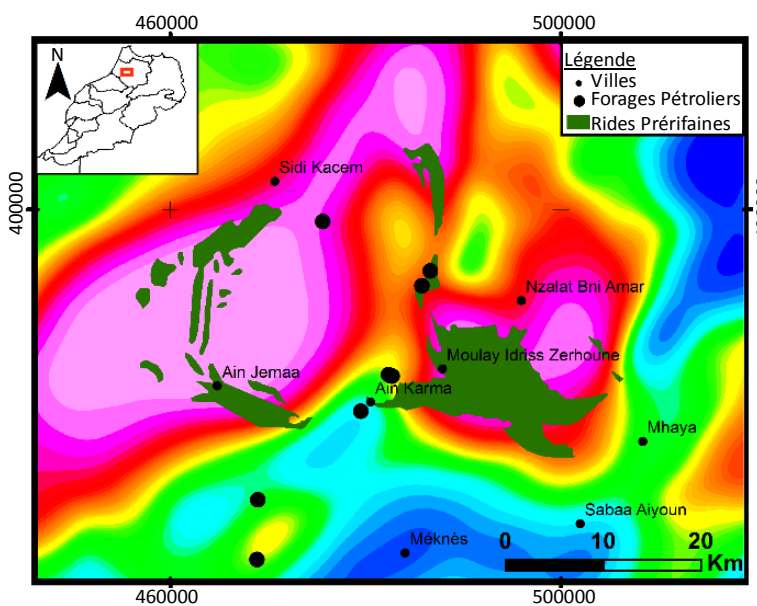

(c)

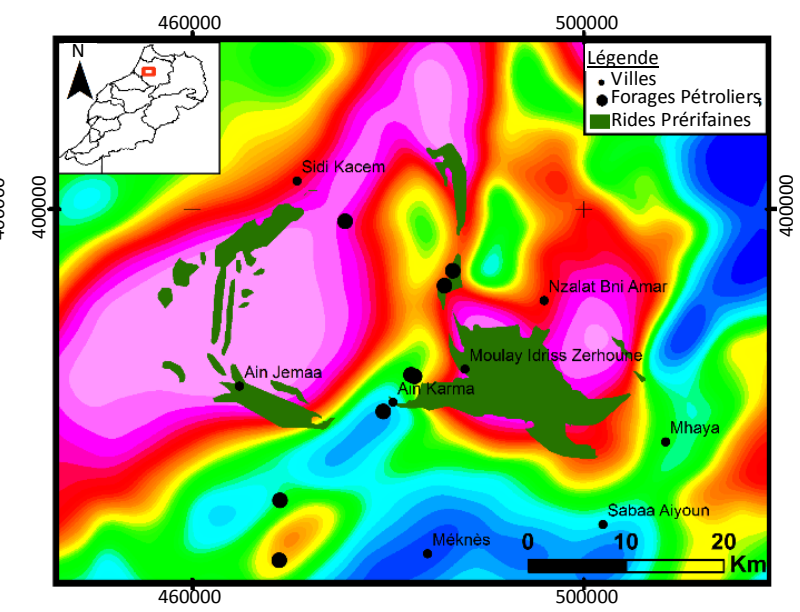

(b)

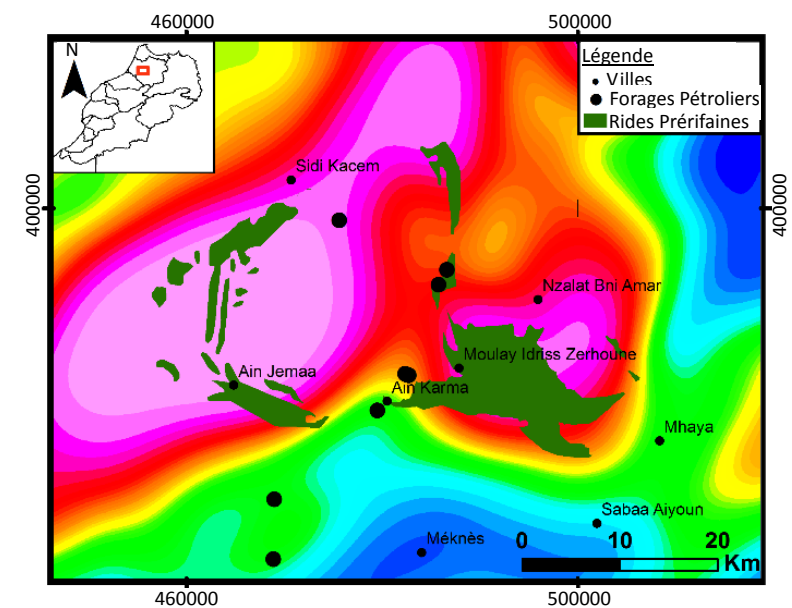

(d)

Figure 8. Maps of the up continuation of the residual anomaly at different altituds. (a) Map of the residual anomaly up continuation to $250 \mathrm{~m}$; (b) Map of the residual anomaly up continuation to $1000 \mathrm{~m}$; (c) Map of the residual anomaly up continuation to $2000 \mathrm{~m}$; (d) Map of the residual anomaly up continuation to $4000 \mathrm{~m}$. 


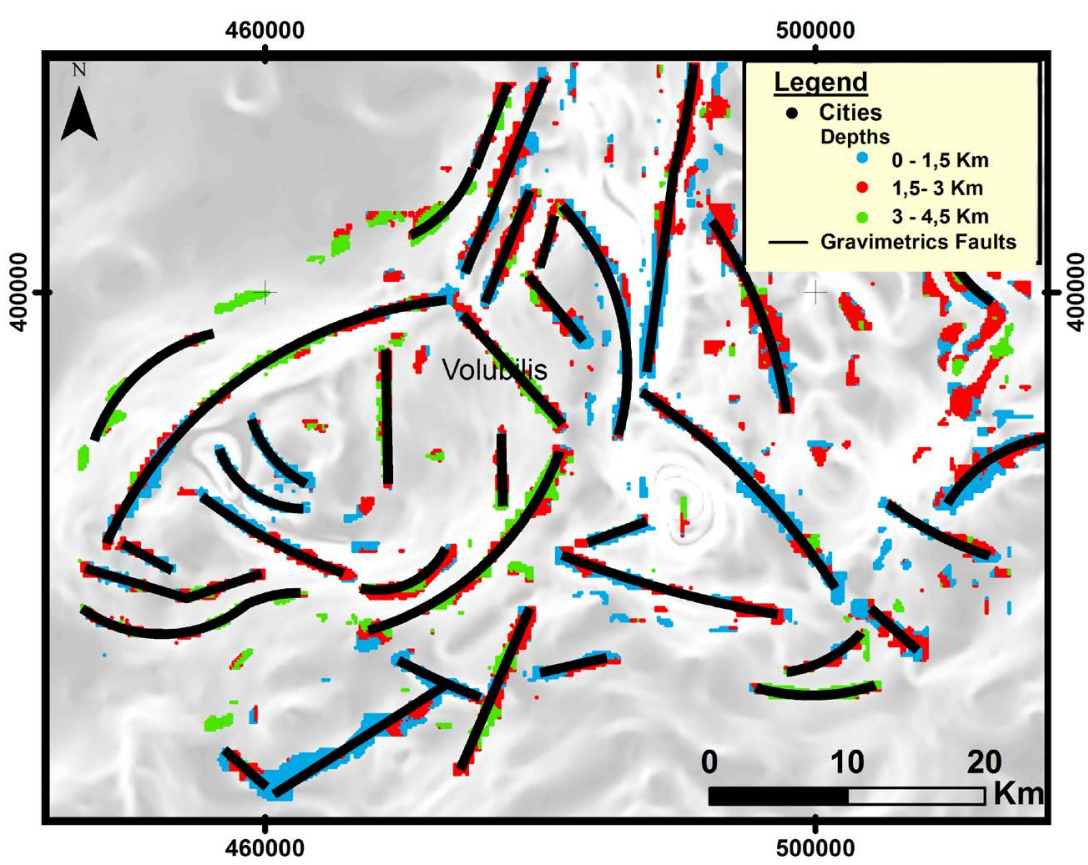

Figure 9. Map of the Euler solutions: SI = 0.5, tolerable error 15\%.

The derived maps perfectly delineate the contours of the anomalies of Eastern and Western ridges, the basin of Volubilis is fairly well individualized. Ridges are separated one from another by Neogene filled synclinal depressions. The new interpreted data allow a better understanding of the distribution of electrically resistive intervals (potentially aquifer). According to this new geometry, those horizons are continuously parallel to the Eastern ridges and show no subequatorial protuberances except in some parallel places to river R'dom. It results, as well, in the fact that the area with electrically conductive horizons (instead of negative anomalies) took all the time a constant geometry, excluding any possibility of those horizons to contain any exploitable water content.

\section{Conclusions}

The principal results obtained from this work allow more understanding of the underground of the prerifaines ridges and Volubilis basin. The principal results are:

- The qualitative interpretations of the residual anomaly show the relation between the positive anomalies and the upcoming of the socle, and the relation between the negative anomalies and the sedimentary basins;

- The establishment of the lithostratigraphy of the petroleum boreholes in this area confirms that the Volubilis basin is due to a upcoming of the socle anomaly,

- The families of accidents of direction NE-SW, NW-SE and N-S, determined in the zone of study are in good agreement with the results of the classic structural studies. These directions are globally well correlated with the Pan-African structuring. The direction N-S achieves shallow depths and remains superficial (recent age),

- The possibility to exploit the groundwater is probably on the NE part of Volubilis basin, so the future prospections can be realized in this area.

\section{Acknowledgements}

We would like to thank the National Office of Electricity and Potable water (ONEE-Water Sector), the Minister of Energy, Mine Water and Environment—Rabat and the Hydraulic Basin Agency of Sebou who provided us with the necessary database for the fulfillment of this study.

\section{References}

[1] Faugères, J.C. (1978) Southern Rifan Ridges. Sedimentological and Structural Evolution of an Atlantico-Mesogean Basin of African Margin. Thesis, University of Bordeaux I, Talence, 480 p. (In French) 
[2] Dauguin, F. (1927) Contribution to the Geological Study of the Prerifaines Region (Morocco Central Part). Note of the Service of Mines and the Geological Map, Morocco 1, p. 413. (In French)

[3] Vidal, J.C. and Faugères, J.C. (1975) New Interpretation of the Southern Rifian Ridges (Rif, Morocco): Role of StrikeSlip Faults. Report of Scientific Academic, Paris, pp. 281, 1951-1954. (In French)

[4] Haddaoui, Z. (2000) The Influence of the Jurassic Geometry Basin on the Neogene over Thrust Propagation: MesoCenozoïc Geodynamic of Southern Ridges (Morocco). Geometrical and Numerical modeling. PhD. Thesis, University Mohammed V, Rabat, 425 p. (In French)

[5] Bargach, K. (2011) The Plio-Quaternary Deformations in the Frontal Part of the Thrust Belt of the Rif (Prerifaines Ridges and Saïs Basin), an Example of the Tectonics in Expelled Corners. Thesis, Mohammed V University, Rabat, 215 p. (In French)

[6] Zizi, M. (1996) Triassic-Jurassic Extensional Systems and Their Neogene Activation in Northern Morocco, the Ridges Prerifaines and Guercif Basin. Ph. D. Thesis, Rice University, Houston, 280 p.

[7] Levy, et al. (1952) Septentrional Morocco (Rif thrust belt). 19ème Congress Geol. Inter. Alger, Part B, Livre-Guide, SCP, Morocco, No. 8 A31, et C31, 65 p. (In French)

[8] Suter, G. (1965) The Region of Average Ouargha (Rif, Morocco). Preliminary Study on the Stratigraphy and the Tectonics. Notes and Memory of Geologic Service, Morocco, No. 183, 7-11. (In French)

[9] Morley, C.K. (1986) A Classification of the Thrust Fronts. Bull. A.A.P.G.70, No. 1, 12-25.

[10] Leblanc (1986) Strike-Slipe Plats in the Rifan Front, a Model for the Deep structure of Prerif (Morocco). Review of the Dynamic, Geologic, Geography and Physical; Paris, 27, 3746. (In French)

[11] Telford (1990) Applied Geophysics. Cambridge University Press, Cambridge, 770 p.

[12] Vanié, L.T.A., et al. (2005) Contribution of the Filterings of the Gravimetrics Anomalies in the Study of the Deep structures of Oriental Morocco. Bulletin of the Scientific Institute, Rabat, Section Sci. Earth, 27, 29-40. (In French)

[13] Company Cherifienne of Petroleum (1955) Note about the Plan of the Residual Anomaly Map Drafted by Diemer for the Company of Prospecting Geophysics Executed by the African Company of Geophysics. (In French)

[14] Thompson, D.T. (1982) A New Technique for Making Computer-Assisted Depth Estimates from Magnetic Data, Geophysics. EULDPH, 47, 31-37.

[15] Hydraulic Basin Agency of Sebou (2001) Report of the Geophysics Study by Electrical Method in the Moulay Driss Zerhoun Region, Unpublished Report. (In French) 